First Peoples Child \& Family Review

A Journal on Innovation and Best Practices in Aboriginal Child Welfare Administration,

\title{
The Maltreatment and Adolescent Pathways (MAP) Project: Using Adolescent Child Protective Services Population-Based Research to Identify Research Questions
}

\author{
Christine Wekerle, Eman Leung, Anne-Marie Wall, Harriet MacMillan, Nico \\ Trocmé and Michael Boyle
}

Volume 3, Number 2, 2007

Special Issue: Adolescent development, mental health, and promising research directions for Aboriginal youth

URI: https://id.erudit.org/iderudit/1069461ar

DOI: https://doi.org/10.7202/1069461ar

See table of contents

Publisher(s)

First Nations Child and Family Caring Society of Canada

ISSN

1708-489X (print)

2293-6610 (digital)

Explore this journal

Cite this article

Wekerle, C., Leung, E., Wall, A.-M., MacMillan, H., Trocmé, N. \& Boyle, M. (2007). The Maltreatment and Adolescent Pathways (MAP) Project: Using Adolescent Child Protective Services Population-Based Research to Identify Research Questions. First Peoples Child \& Family Review, 3(2), 43-49.

https://doi.org/10.7202/1069461ar

\section{Article abstract}

This article introduces readers to the Maltreatment and Adolescent Pathways (MAP) study. The MAP is a longitudinal study that follows active case files of mid-adolescents in a large urban child protective services (CPS) system. The MAP is a unique opportunity to collect information from teens about their physical health (e.g., sleep quality), mental health (e.g., posttraumatic stress disorder) and cognitive style (e.g., attention, memory). The MAP study samples the population of CPS teens on questions that are used in provincial teen surveys, allowing for points of comparison to non-CPS teens. The MAP tracks youth development over 2.5 years. Although the MAP currently has a very small number of Aboriginal teens, the responses of these teens may focus practitioner and researcher attention to priority areas for further research. This includes the investigation of how some research issues, such as maltreatment history, personal safety, relationship to primary CPS worker and suicidal ideation, may be cross-informative. It is known that teen risk behaviours cluster together, but it is important to understand the relationships among these variables. An understanding of these relationships can drive knowledge creation, as well as practice and policy change. Finally, the MAPstudy has succeeded given a successful collaborative partnership between hospital, university, and CPS partners who both strive to keep the youths' best interests in the forefront.
Copyright (C) Christine Wekerle, Eman Leung, Anne-Marie Wall, Harriet MacMillan, Nico Trocmé, Michael Boyle, 2007
This document is protected by copyright law. Use of the services of Erudit (including reproduction) is subject to its terms and conditions, which can be viewed online.

https://apropos.erudit.org/en/users/policy-on-use/ 


\title{
First Peoples Child \& Family Reviex
}

A Journal on Innovation and Best Practices in Aboriginal Child Welfare Administration, Research, Policy \& Practice

\section{The Maltreatment and Adolescent Pathways (MAP) Project: Using Adolescent Child Protective Services Population-Based Research to Identify Research Questions}

\author{
Christine Wekerle ${ }^{a}$, Eman Leung ${ }^{a}$, Anne-Marie Wall ${ }^{b}$, Harriet MacMillan ${ }^{c}$, Nico Trocméd $^{\text {, }}$ \\ and Michael Boyle
}

${ }^{a}$ Faculty of Education, Department of Psychology, University of Western Ontario, London, ON, Canada

${ }^{b}$ Department of Psychology, York University, Toronto, ON, Canada, now deceased

c Offord Centre for Child Studies, McMaster University, Hamilton, ON, Canada

${ }^{d}$ Faculty of Social Work, McGill University, Montreal, QUE, Canada

\section{Introduction}

Childhood maltreatment - sexual, physical, emotional abuse and the physical and emotional neglect - is an experience that has been associated with a wide range of challenges across development (see Wekerle, Miller, Wolfe, \& Spindel, 2006 for a clinician's resource book). The most severe outcome is suicide, where much is lost, including the opportunity for the health care community to actively intervene and provide the support a youth requires to self-right and craft

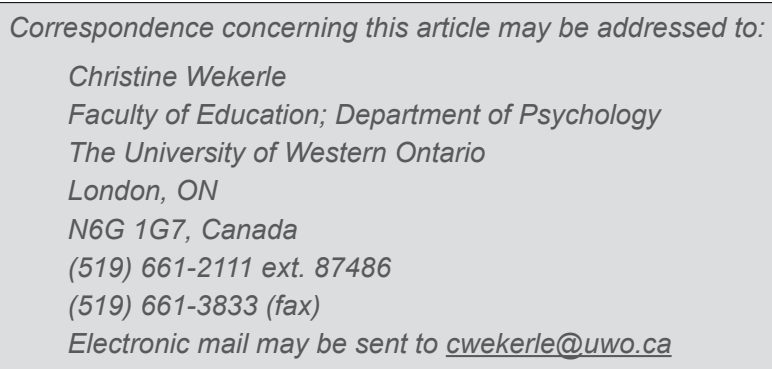

\begin{abstract}
This article introduces readers to the Maltreatment and Adolescent Pathways (MAP) study. The MAP is a longitudinal study that follows active case files of mid-adolescents in a large urban child protective services (CPS) system. The MAP is a unique opportunity to collect information from teens about their physical health (e.g., sleep quality), mental health (e.g., posttraumatic stress disorder) and cognitive style (e.g., attention, memory). The MAP study samples the population of CPS teens on questions that are used in provincial teen surveys, allowing for points of comparison to non-CPS teens. The MAP tracks youth development over 2.5 years. Although the MAP currently has a very small number of Aboriginal teens, the responses of these teens may focus practitioner and researcher attention to priority areas for further research. This includes the investigation of how some research issues, such as maltreatment history, personal safety, relationship to primary CPS worker and suicidal ideation, may be cross-informative. It is known that teen risk behaviours cluster together, but it is important to understand the relationships among these variables. An understanding of these relationships can drive knowledge creation, as well as practice and policy change. Finally, the MAP study has succeeded given a successful collaborative partnership between hospital, university, and CPS partners who both strive to keep the youths' best interests in the forefront.
\end{abstract}

a life of vitality. Beyond suicide, behaviours such as depression, anxiety, and panic; aggression and delinquency; sexual risk-taking; and substance misuse are among the most common mental health issues.

Whenever these behavioural concerns emerge, family violence immediately becomes a clinical hypothesis to consider in assessment. During these assessments, the question about maltreatment needs to be asked directly, and needs to be asked in terms of specific behaviours (e.g., were you hit to the point of 


\section{Author Notes}

The MAP Longitudinal Project is supported by CIHR Institute of Gender and Health (IGH); ON Centre of Excellence in Child and Youth Mental Health at CHEO, and a CIHR NET grant on the impact of child maltreatment on adolescent and adult health outcomes. The MAP Feasibility Study was funded by CIHR/CAHR; Centre of Excellence in Child Welfare, Public Health Agency of Canada. We acknowledge CIHR IGH/Ontario Women's Health Directorate Mid-Career Award to Dr. Wekerle. We thank all the youth participants, all the caseworkers involved, and our MAP Advisory Team, without whom there would be no MAP project. We acknowledge Advisory members from the Children's Aid Society of Toronto (Deb Goodman, Rory Gleeson, Barry McKendry, Lori Bell, David Firang, Darlaine Mathews, Dan Cadman, Angie Corrado); the Catholic Children's Aid Society of Toronto (Bruce Leslie, Tara Nassar, Mario Giancola, Coreen Van Es, Sean Wyers, Bervin Garraway, Jacqueline Bittencourt); the Peel Region Children's Aid Society (Brenda Moody); and MAP Research Staff (Janu Gopalapillai, Solmaz Zanjani, Meghan Tyrrell, Chester Ylagan, Jennifer Fong).

bruising or leaving marks? Did the individual touch your private parts?), rather than using general terms like "abuse" or "neglect" with a youth. The use of these general terms requires an element of willingness by the youth to self-label as abused or neglected, as well as knowledge of the broader context of normative parenting. It is important to directly inquire about maltreatment as waiting for a disclosure is often not sufficient support to a child or youth who just wants the abuse to stop. The experience of maltreatment suggests that something went wrong in the family, in terms of injury prevention and protection. If the question of maltreatment is not asked, then the opportunity to provide a safety net for a family that has become isolated, insulated, impoverished and impulsive has been lost. This family needs support in (re)learning alternatives to violence.

While the maltreatment may have ended before adolescence, transitioning to genuine maturity and self-care may be challenging. Maltreatment may be felt with each developmental step: finding a best friend, developing supportive social networks, entering dating, having a romantic partner, believing in yourself enough to take on challenging career and educational opportunities, and confronting any mental health issues directly. Given the leveraging that comes with so many changes, including physically and neurodevelopmentally, adolescence is a window of opportunity. To be in the position to set a positive track, it helps to have a map or layout of where the common pitfalls are and what are strong options for health. When roadblocks are encountered, the youth needs to know how to best to go about changing and coping.

One of the goals of directing Aboriginal youth who come to the attention of the child protective ser- vice system is to provide a point of cultural contact and facilitate opportunities to foster a positive identity with Aboriginal culture(s), in addition to working on individual youth issues. This article introduces the Maltreatment and Adolescent Pathways (MAP) project, a study that can inform us on teen perceptions of their world. Here, we focus on what teens' are identifying as their individual issues and connect these to research questions that could be considered in the future.

\section{The MAP Study}

To date, 218 child protective services teens (54\% female), aged 14 to 17 (average age $=15.5$ years), have taken part in the MAP study by completing an initial testing. The youth who have participated in the study described their ethnicity as: $38 \%$ Caucasian, 33\% Blacks, 2\% Aboriginal; 13\% Other; 14\% Bi/ Multiracial. Youth were living with foster parent(s) $(33 \%)$, biological parent(s) $(24 \%)$, in a group home $(30 \%)$, or some other arrangement $(13 \%)$. Teens involved in the MAP study are tested every 6 months for 2.5 years. During these sessions, the youth fill out nearly 100 pages of self-report questionnaires, usually in their homes. These questionnaires ask youth about their socioeconomic status, drug and alcohol use, dating practices, friendships, sexual practices, psychological health, maltreatment history, and resiliency. The MAP has demonstrated a 70\% recruitment rate and a $90 \%$ retention rate of all youth with active and eligible files within a major urban centre. About $60 \%$ of youth in the MAP study report experiencing physical and emotional abuse, 40-50\% neglect, and $20-25 \%$ sexual abuse. The rates of childhood maltreatment in the MAP exceed what would be expected based only on the profile of new cases at intake in Canadian child protective services as per the Cana- 
dian Incidence Studies (CIS-I, CIS-II) of Child Abuse and Neglect. This discrepancy could be explained in terms of the MAP asking about abuse and neglect across the childhood years.

The MAP is not a national study, but attempts to capture the youth population in Toronto, Ontario. In Ontario, the child protective services system is managed by local Children's Aid Societies (CAS) that have geographical catchment areas and, in the case of the city of Toronto, mandates based on identified religion. The MAP study is past the time frame when most of the Aboriginal Toronto-area Children's Aid Society cases in care have been transferred to the local Native Child and Family Services. Present practice dictates that any intake cases with Aboriginal children or family members are directed to their culturally appropriate services (as is the case with identification by religion, specifically, Catholic and Jewish, with all remaining cases going to Children's Aid Society of Toronto). The MAP study is currently involved with 3 agencies in the Toronto area: Catholic Children's Aid Society (CCAS), Children's Aid Society of Toronto (CAST), and Peel Region Children's Aid Society (Peel). The MAP does not have the participation of youth with the Native Child and Family Services in Toronto. The MAP has approached the Toronto smaller agencies about involvement in the study; however, the workload involved in providing liaison members and accommodating the research involvement were not feasible as determined by the agency representatives. Service issues and resources prevent the substantial commitment that the MAP requires in these smaller agencies. Feasibility to participate for the agency is an important decision and is, in and of itself, a research question to clarify parameters for involvement for future research efforts.

A remaining need is how best to support agencies to engage in research, within Canadian funding trends. In the MAP study, honoraria are provided to all agencies on the basis of 10 eligible youth referred for involvement in the study, even if the youth do not consent to participate. CAS agency advisory board members assume this MAP-dedicated time within their CAS workload, given agency administrative approval for the MAP study. At present, direct payment for research involvement by the CAS agencies is not a feasible approach considering the funding caps on Canadian grants. The MAP participating ser- vice agencies can expect "reimbursement" for their involvement in the study via access to clinician-scientist expertise and access to systems of research literature and support, such as a literature searches with attached seminal articles on an issue of practice importance. The MAP has a list serve to circulate timely articles and evidence-based practice opportunities, and delivers clinical workshops to CAS agencies in youth service topics areas.

\section{Governing the Research: Partnership for the Youths' Best Interests}

The MAP study is guided by a community-researcher partnership. The MAP advisory board represents CAS workers, researchers within the agencies, and university- or hospital-based clinician-scientists and researchers. The academic group is interdisciplinary, with representation from child and family clinical psychology, adult clinical psychology, experimental psychology, pediatrics, child psychiatry, social work, and epidemiology. The advisory group meets regularly - monthly for the first start-up year of the study and bimonthly thereafter. Joint activities include the review of every item and measure included in the MAP study, identifying new research areas to consider, creating and reviewing the testing and clinical follow-up procedures, developing the consent forms for the study (with the help of a CAS lawyer), and providing supporting letters to University Internal Ethics Review Boards to help clarify required or recommended procedures that may be beyond standard ethics practices. This is sometimes necessary given the nature of the population included in the study.

The MAP Advisory Board worked to create practices that maximally supported youth. Researchers wanted to measure youth distress as a function of research participation and, as such, inserted a series of ratings before and after each testing session. Results showed that MAP youth were no more distressed after being in the research than before they started a testing session. CAS workers wanted to ensure research participation had a non-exploitation conceptualization, and was viewed along the lines of a work opportunity. For example, workers were very clear that the best remuneration for study participation would be money, not coupons for music or food items. The youth's time is reimbursed with money and the MAP feasibility study set the longest time a youth needs for testing, and all youth were paid to that level. Traditionally, 
though, ethics boards would see any monetary gift as coercive or potentially damaging (e.g., youth could buy drugs). Feasibility analyses indicated that money was the most often noted reason by youth for participating, but it was not the sole reason endorsed. Other reasons included interest in the research topic and a desire to help others.

Traditionally, ethics boards would also argue that approaching youth to inquire about involvement in the study via CAS workers may foster too close an association with the agency and may be experienced as coercion to the youth. However, all CAS workers used a standard script of a few sentences and were not responsible for answering questions or providing much detail about the MAP study. The caseworker obtained telephone consent for research staff to take on this role where it is clarified several times that services are not affected in any way by a decision to participate or to not participate in the study. It was important to limit initial external contact with the youth by MAP researchers since CAS teens are identified as a population in need of protection. CAS workers were the first individual to contact CAS youth about the study to support a sense of control and limit vulnerability in the population. These examples demonstrate the desire of researchers and CAS agencies to support the best interests of the CAS youth, which meant documenting the rationale for deviating from the norm for university-based research ethics boards. The MAP has been approved by CAS, hospital-based and university-based research ethics boards.

\section{The MAP Study: Research Suggestions from Aboriginal Youth Responses}

To date, 5 youth in the MAP study have identified themselves as being Aboriginal. Currently, analyses can not proceed given this small number, and significant findings as compared to non-Aboriginal MAP youth can suggest trends to provide material for further thought about research questions. Thus, these "results" should not be taken as important in and of themselves, but rather serve as a basis for further discussion of research needs.

Clinically, it is a truism that productive change will not be maximized if one only targets problem behaviours. Both sides of a behaviour need to be defined - what not to do and what to do - where the positive side is practiced to produce skills at the level of a "ready response." Optimal functioning includes the person's own view of how they are doing, all things considered. It can include approaches to life, such as hopefulness, optimism, forgiveness, and wisdom. It can also include community-based behaviours like "helping out," being responsible, and feeling safe. Often taking a back seat in child welfare practice is "productive leisure," such as exercise, crafts, music, sports, dance and other arts. These activities provide an opportunity for skill-development, mastery, and earning money, in addition to enjoyment, distraction, and relaxation.

There are roles for intentional, planned actions, as well as opportunities for spontaneous engagement. Essentially, youth have to feel engaged in living, have ideas (even vague ones) about a future for themselves, and have supportive relationships. Youth need to understand that they are not alone in their maltreatment and that there are options to prevent other victimizations, be they at school, in dating partnerships, at social events, or with their families and communities. Some youth may need to be "coached" towards accepting help, counteracting thoughts of personal weakness with personal power in taking charge of the issues that are affecting them. Below are three wellbeing issues that the MAP study considers.

\section{Felt Sense of Safety}

Child welfare has always been organized first around child protection. It would seem of interest, then, to understand how protected children and teens feel in their many environments. Even at school, the caregiver plays a key role as advocate in cases of school bullying which can become chronic and has led to maladjustment and, even fatal outcomes. Failures to protect extend beyond the family home to the key environments of school and neighbourhood. Child protection service workers also play a liaison role with schools and communities and can join in family problem-solving on these issues. MAP findings suggest that:

- MAP Aboriginal youth tend to report feeling safe in their neighbourhoods and homes more so than non-Aboriginal MAP teens. Overall, though, $90 \%$ of MAP youth feel safe in their neighbourhoods. Further information on the population of high school youth in Ontario (grades 7 to 12) is available from the Ontario Student Drug Use Survey Study at http://www.camh. net/research/osdus.html.

- More MAP Aboriginal youth seemed to feel less safe 
in school (25\%) than do non-Aboriginal MAP youth $(12 \%)$. This is substantially higher than the Ontario population of high school youth, where only $6 \%$ say that they do not feel safe in school.

Possible questions for future research include:

- What contributes to a youth's felt sense of safety in the environments of their daily lives?

- How does a felt sense of being unsafe in school and in one's neighbourhood impact cognitive functioning, such as the ability to focus attention, move information from short-term memory to long-term memory stores; and "work" or manipulate information for problem-solving?

- How does their maltreatment experiences impact personal safety? Is post-traumatic stress response, including symptoms like hypervigilance and avoidance of trauma-connected cues, maintained in day-to-day life via daily stressors?

- Have youth acquired effective personal safety skills? How does their felt sense of safety influence their style of relating? Do youth feel like they can bring up school safety issues with their workers? Bullying is often related to younger age children, but harassment about sexual orientation and sexual bullying (e.g., giving "up-down" stares or rumors about sexual activity) are prevalent in high school.

\section{Attachment to Care Providers}

The stylistic way of relating is still under development in adolescence. It is known that maltreated infants are mostly classified as disorganized in their attachment, meaning that they have low confidence in their caregiver providing a sensitive response and do not have an organized, coherent response to caregivers (see Wekerle et al., 2006 for a review of the literature). It also means that the child is never clear on how best to respond to minimize threat and maximize the ability to stay close to his or her attachment figure. It is important to remember that even if it is insecure or problematic, virtually all children form an attachment bond. Sometimes, the maltreated child avoids the caregiver and pay attention to other things, like T.V., toys, or schoolwork if he can remove himself from the caregiver environment. Sometimes, the maltreated child protests the caregiver's unsatisfactory behaviour, like "getting in their face" or affection attempts that hurt (e.g., giving a too-tight hug). Essentially, the maltreated child has difficulty trusting in relationships since the person they are relating to is so hard to "read." The child may feel that relating is unpredictable, does not often feel good or make them feel good about himself or herself, seems to be outside of any control. Or, the child may overcompensate by trying to become overly controlling, overly compliant, or overly caring in their environment. Mistrust, fear, overly quick engagement and closeness, and easily dropped attachments may come to describe maltreated children's relationships. The primary child protection service worker is one opportunity to provide a context for relationship modeling and learning a new style of relating. Listed below are comments that the MAP teens have made about their workers.

- MAP Aboriginal youth are less likely than non-Aboriginal MAP youth to endorse that they have strong feelings toward their primary worker and feel that the worker is not very important to them. Overall, $27 \%$ of MAP youth disagree to some extent with the statement that their worker is important to them. Thus, most youth would seem to feel a positive connection or valuing of their worker, but a substantial number do not.

Possible research questions include:

- How does felt safety and demonstrated support factor into the youth's view of their relationship to their primary worker? Is this influenced by the number of worker changes? Do youth feel that they are empowered to continue their interaction with a worker with whom they feel connected?

- Who are the workers that are valued? Those who convey affection and positive regard for the youth as a whole? Those that celebrate and validate important dates in the youth's life? Those that actively work at inspiring and mentoring youth? Those that actively support the limit-setting and fair behaviour correction practices?

- One research question would be to better understand how there is a successful interplay between worker relationship and relationship investments in strong community-based support?

\section{Thoughts of Suicide}

Suicidal thinking does not necessarily reflect a wish to die. However, it is a predictor of suicide attempts and deaths, as well as mental health concerns. The risk of suicide is heightened when there is substance abuse, depression, prior suicide attempts, a plan of action, easy access to suicide means, and fewer obstacles to suicidal actions. All verbal and non-verbal threats of suicide, such as drawing of hanging oneself and writing on school binders of sui- 
cidal thoughts needs to be further followed up in all cases. Below are some findings of suicidal ideation among the MAP youth.

- MAP Aboriginal youth tend to have greater thoughts about ending their life than non-Aboriginal MAP teens. In the MAP overall, 26\% experienced suicidal ideation, with $13 \%$ thinking of ending their life "quite a bit" or "extremely." As a point of comparison, the OSDUS 2001 study reports that $11 \%$ have serious suicide thoughts, substantially lower than MAP teens (see the OSDUS E-Bulletin Report at: http://www. camh.net/Research/Areas_of_research/Population Life_Course_Studies/eBulletins/eb018_suicide.pdf.) Further, the OSDUS study shows that teens who report thinking about killing themselves also tend to live in a single parent home, have lower parental monitoring, report poorer relationships with their parent, report not feeling as safe at school, have low attachment to school, and are victims of school bullying.

Potential useful follow-up research ideas include:

- What is the context for suicidal thinking and self-harm actions? Are these daily occurrences? Do they match up with "dips" in mood or negative events, such as relationship conflict? Do they occur in the context of substance use? Do friends have these or talk about it?

Research with an Ontario population of adults indicated that the risk of suicidal ideation more than doubles among adult depressed women when they have experienced childhood physical abuse, as compared to those women who have not (McHolm, MacMillan, \& Jamieson, 2003). In a population study of teen females in the US, it was found that girls who were "experimenters" (i.e. those that are more likely to have sex, use drugs, or drink alcohol) were 2-3 times more likely to be depressed one year later (Halfors, Waller, Bauer, Ford, \& Halpern, 2005). Depression initially did increase the likelihood of moving from an "experimenting" group to a "high risk" group. For boys, binge drinking and frequent marijuana use predicted subsequent depression. Thus, it would seem that for girls, depression prevention may involve sex education regarding intercourse and multiple partners and alternatives to substance use. A gender-specific consideration of the effects of maltreatment is a research area that has been under-considered to date.

Other important research questions related to suicide ideation include what protective factors are in the community to reduce suicidal thinking and risk for action. Further, understanding the youths' reasons for living (family, friends, future, specific plans/goals) versus reasons for dying (escape oneself or others/relationships, feeling hopeless) would seem important to understand from both a motivational set. For youth who repeatedly think about suicide, it would be important to understand what is the nature and sequence of their inner cognitive debate, if there even is a selfdialogue that occurs, or why death seems an attractive option.

Morsette (2006) indicates that Native American humor seems embedded in the culture and in no way depreciates the gravity of situations. As with maltreatment, verbal "testing of the waters" in terms of disclosing suicidal thinking may be relayed in a humorous story. Morsette notes that dealing with an individual issue means being cognizant of the relation of the self to families, elders, and social/local norms. Any statement of suicide needs to be followed up, regardless of a humorous delivery or in the context of a humorous anecdote, and a suicide risk assessment completed (see ...). Quite simply, without the youth alive, the maltreatment experience is not fully appreciated and validated, and opportunities to intervene effectively are no longer available. Clinically, when thoughts of suicide lead to a sense of inner calm or has the person smiling, the youth needs support in addressing their affect, and re-engaging and building new positive reinforcing activities.

The day-to-day life of a teen should involve more positive experiences than negative. Otherwise, the job of child protective services is not complete. Child protective services need to be concerned with the daily lives of their youth - how safe they feel, how well they are sleeping and eating, how connected and supportive their relationships are, and whether or not they feel that they are moving toward specific goals and dreams. Some areas of concern have been examined in this paper, but there are many more areas of concern documented by the results of the MAP study. For example, about half of MAP youth tell us that they have difficulty dealing with explosive anger and can't stop thinking about bad things that have happened to them on a weekly basis. The experience of childhood maltreatment forces youth to sometimes find ways of coping in advance of skill development. It challenges their ability to form a "story" of their maltreatment by integrating information from different perspectives and sense-based information, especially when fear is strongly linked to abuse/neglect memories. 
It should not be surprising, then, that the MAP youth report that for those teens who are drinkers and smokers, they began their drinking, smoking and use of marijuana before age 13. Nearly half of the MAP youth have had their first "wanted" intercourse by age 14. Among these teens, $5 \%$ say that they in fact did not want their first sexual intercourse and $43 \%$ say they were unsure about it. Furthermore, about 30\% of the MAP youth had intercourse in the past year with someone they did not know well. Thus, while for most MAP teens their maltreatment experiences were in the past, our analyses show that it is related to what they do in the present and how they get through adolescence as a developmental stage. Rather than over-focusing on independence and the providing of information on surface levels (i.e., use pregnancy and disease protection with every intercourse), we may need to return our attention to focusing on guidance at the level of the whole person (i.e., what kind of partner do you want to have?). Simultaneously, it may be important to remain mindful of daily functioning with the knowledge that adolescence is a bridging between childhood and adulthood. Allowing the "child" in the teen to remain active by discouraging the rush toward "adult-like" behavior (i.e., remaining curious, appreciating discovery, and having harmless fun) may be another important way of supporting our teens involved in the child protective services system. In this way, we all hope that the teen will not just survive to adulthood, but thrive.

\section{References}

Halfors, D. D., Waller, M. W., Bauer, D., Ford, C. A., \& Halpern, C. T. (2005). Which comes first in adolescence - sex and drugs or depression? American Journal of Preventive Medicine, 29 (3), 163-170.

McHolm, A. E., MacMillan, H. L., \& Jamieson, E. (2003). The relationship between childhood physical abuse and suicidality among depressed women: Results from a community sample. American Journal of Psychiatry, $160(5), 933-938$.
Morsette, A. (2006). Cultural differences influence trauma treatment in Native American populations. Traumatic Stress Points. (available from: www.istss.org).

Trocmé, N. (2005). Canadian Incidence Study of Child Abuse and Neglect - 2003: Major Findings. Minister of Public Works and Governmental Services Canada.

Wekerle, C., Miller, A., Wolfe, D. A, \& Spindel, C. (2006). Childhood Maltreatment. Volume in Advances in Psychotherapy - Evidence-Based Practice Series, New York, NY: Hogrefe \& Huber. (Continuing Education Credits offered through the American Psychology Association, Clinical Psychology Division). 